\title{
Need for services for the care and prevention of congenital disorders in South Africa as the country's epidemiological transition evolves
}

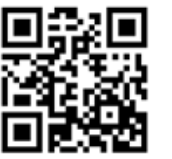

The lack of prioritisation of congenital disorders (CDs) in healthcare, and the limited resources allocated to prevention and to the care of those affected, is an issue of global concern. This is especially true in low- and middle-income countries (LMICs), where over $90 \%$ of CDs currently occur, resulting in $95 \%$ of CD deaths worldwide. ${ }^{[1,2]}$

In 2010 the World Health Organization's World Health Assembly (WHA) prioritised services for the care and prevention of CDs, particularly in LMICs, by passing Resolution WHA63.17. ${ }^{[2]}$ This recognised the importance of CDs as a cause of stillbirths and neonatal deaths, their contribution to under-5 mortality, and their contribution to failure to attain Millennium Development Goal 4 (MDG4). WHA63.17 urged member states to recognise and address $\mathrm{CDs}$ as a public health issue. It also highlighted the lack of accurate epidemiological data available for many LMICs. ${ }^{[2]}$ CDs are often undiagnosed or misdiagnosed and the cause of death wrongly attributed. Collectively, this prevents policy decision-makers from correctly assessing the burden of CDs in these LMICs. ${ }^{[3]}$
In South Africa (SA), the constitutional, legal and regulatory framework exists to promote the development of services for the care and prevention of CDs. It is the government's responsibility to provide such services. To understand the renewed need for these services, it is important to consider, contemplate and review the epidemiological transition that has occurred in SA over the last 25 years.

\section{Epidemiology of CDs in SA}

Modelled data of genetic causes of $\mathrm{CDs}^{[1]}$ and an estimate of teratogenic causes (A L Christianson, personal communication, 2014 ) indicate that a minimum of $6.8 \%$ of births, representing one in every 15 live births in SA, is affected by a CD. Of these, $80.5 \%$ are genetic or partially genetic in cause, while $19.5 \%$ are caused by teratogens. The latter is higher than the $10-15 \%$ expected, owing to the high prevalence of fetal alcohol syndrome. ${ }^{[1]}$ With $26.2 \%$ of CDs diagnosable in the first day of life, over 18000 cases annually should be identified and reported in SA. ${ }^{[4]}$ However, in 2012 only 2174 CDs were reported via the Birth Defects Collection Tool administered by the National Department of Health (NDoH) (V Mtyongwe, 
personal communication, 2013). This indicates under-reporting of $88 \%$ !

Although serious CDs can be life threatening or result in longterm disability, up to $70 \%$ can be prevented, cured or ameliorated by appropriate care. ${ }^{[1,5]}$ Many interventions are relatively inexpensive and low-tech, including surgery for congenital malformations and community-based preventive measures (e.g. iodine and folic acid fortification of staple foods). ${ }^{[1]}$

\section{Epidemiological transition}

Epidemiological transition is the term for the change in population health statistics and pattern of diseases of a country or region, consequent on change in socioeconomic, education, infrastructure and healthcare development. ${ }^{[1]}$ Omran's three-stage model of epidemiological transition ${ }^{[6]}$ has been used extensively to describe this process, particularly in industrialised nations. During this transition, infant and child mortality rates decrease and longevity rises, communicable diseases are controlled and eradicated, and noncommunicable and degenerative diseases emerge.

Most high-income or industrialised countries completed the first two stages of epidemiological transition decades ago. Stage one, the 'age of pestilence and famine', is characterised by high fluctuating mortality rates, a low life expectancy at birth, and epidemics, famine and war as the main causes of death. This is followed by stage two, the 'age of receding pandemics', when mortality starts to decrease and is accompanied by a marked increase in life expectancy, although high levels of communicable disease remain. ${ }^{[6]}$ By controlling infectious diseases, reducing malnutrition and improving healthcare (including maternal) services, industrialised countries moved into stage three, the age of degenerative and man-made diseases. ${ }^{[1,6]}$ Deaths from CDs remain invisible during this process of transition - 'buried' among deaths caused by communicable diseases - to emerge only as the latter are adequately controlled. CDs then become proportionately more significant in overall neonatal, infant and child mortality.
CDs attained public health significance in industrialised nations as they moved into the third stage of epidemiological transition in the early 1960 s. $^{[1]}$ Since $85-90 \%$ of CDs have a genetic cause, their birth prevalence and resulting mortality remained high, ${ }^{[1]}$ causing them to emerge and persist as a leading cause of child death in industrialised nations. A comparative study of death rates in England and Wales for 1901 and 1971 demonstrates this: a $68 \%$ reduction in non-communicable diseases occurred between 1901 and 1971, but the number of deaths caused by CDs remained unchanged. ${ }^{[1]}$

\section{Epidemiological transition and CDs in SA}

SA, like many LMICs, has not followed the classic model of epidemiological transition experienced by industrialised nations, as a result of the HIV/AIDS and TB epidemics. ${ }^{[7]}$ Fig. 1 plots the under-5 mortality rate (U5MR), infant mortality rate (IMR) and life expectancy at birth (longevity) data for SA over the past 25 years. From 1960, a clear trend of decreasing infant and under-5 mortality and increasing longevity continued until 1992, when life expectancy at birth peaked at 62.33 years. In 1993, both the U5MR and the IMR were at an all-time low of 58.2/1 000 live births and 45.1/1 000 live births, respectively. At this point it appeared as if SA would follow the three classic stages of epidemiological transition, approaching the early phases of transition from stage two of the 'age of receding pandemics' to stage three, the 'age of degenerative and man-made diseases. ${ }^{[6]}$

As a result of this falling childhood mortality in the early 1990s, CDs began to emerge as a public health issue. The Policy Guidelines for the Management and Prevention of Genetic Disorders, Birth Defects and Disabilities were published by the NDoH in 2001. ${ }^{[8]}$ These outlined goals, objectives, strategies and delivery of clinical and laboratory services appropriate for the care and prevention of CDs. In 2004, the National Guidelines for the Care and Prevention of the Most Common Genetic Disorders, Birth Defects and Disabilities ${ }^{[9]}$

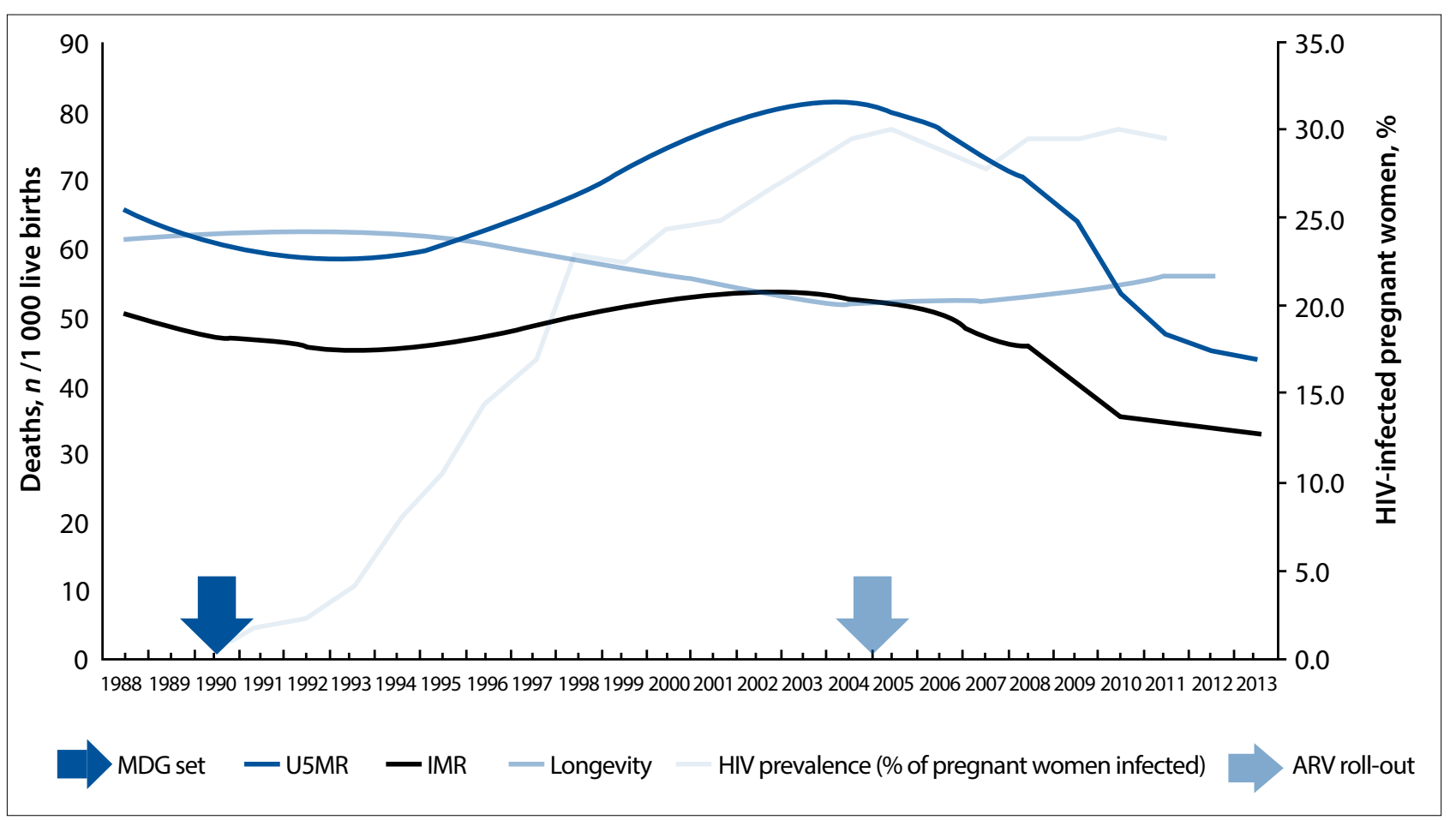

Fig. 1. Epidemiological transition in SA over the past 25 years, as demonstrated by data for childhood mortality, ${ }^{[18]}$ longevity ${ }^{[19]}$ and the HIV epidemic. ${ }^{[20]}$ 
were published, targeting primary healthcare providers, describing common CDs and strategies for their care and prevention. However, progress in epidemiological transition was dramatically interrupted and reversed in the mid-1990s with the advent of the concomitant HIV/AIDS and TB epidemics (Fig. 1). Over a 10-year period, HIV prevalence in pregnant women soared from $7.6 \%$ in 1994 to $29.5 \%$ in 2004. Child mortality rose dramatically, with the U5MR peaking at 80.8/1 000 live births in 2003 and the IMR at 53.2/1 000 in 2002 . Life expectancy dropped to 51.56 years in 2005, an all-time low since the 1960s. SA was no longer following the sequential stages of transition as HIV/AIDS caused the resurgence of TB, adding a stage to Omran's concept known as the 'age of emergent and re-emergent infections. ${ }^{\text {'7,10,11] }}$ Combined with the simultaneously increasing burden of non-communicable diseases in the population, this has led to a 'double burden of disease. ${ }^{[11]}$

In 2004, the prevalence of HIV infection among pregnant women plateaued at $30 \%$ and the U5MR started to reduce as a result of scaledup prevention of mother-to-child transmission and expanded rollout of antiretroviral (ARV) therapy. ${ }^{[12]}$ The 2002 IMR of 53.2/1 000 live births dropped to 33.5 in 2012 (Fig. 1). This is lower than the all-time best IMR of 45/1 000 live births in 1993 prior to the HIV/ AIDS epidemic. However, since 2011 both the IMR and U5MR have stagnated without significant further reductions. ${ }^{[13]}$

A major effect of the HIV/AIDS and TB epidemics was to 'bury' the issue of CDs. As services for HIV/AIDS developed, funding and attention were diverted away from tertiary medical genetic services. If child mortality, including neonatal deaths, is to decrease further, control of these ongoing epidemics cannot be at the expense of other child healthcare needs. ${ }^{[12]}$

Services for the care and prevention of CDs in SA are now at a lower base than in 2001. The 2003 recommendations for human capacity requirements to be trained and in-post by 2010 to meet the expected, and now increased, health needs remain unfulfilled. ${ }^{[14]}$ Personnel levels are similar to, or lower than, those in 2001, with 11 medical geneticists today compared with four in 2001 and the 20 recommended by 2010. ${ }^{[14]}$ Of the nine genetic counsellors in posts today, only four are in the state system ( $\mathrm{T}$ Wessels, personal communication, 2014), compared with approximately 20 in 2001, and the 80 recommended. ${ }^{[14]}$ Budget cuts have compromised medical genetic diagnostic laboratory services countrywide.

In 2013, SA was reported as the only country of eight emerging economies evaluated where positive development in improving medical genetic service structures had ceased and indeed regressed. ${ }^{[3]}$ This decline will take time to reverse, and the dire state of these services, including the lack of policy addressing childhood disability, must be recognised by those in authority and urgently rectified.

\section{Conclusion}

While SA has missed attaining MDG4, it has significantly reduced the U5MR and IMR under difficult circumstances. The previous negative epidemiological transition, premised on the HIV/AIDS epidemic, has reversed and is once again positive with an IMR of 33/1 000 live births. ${ }^{[7]}$ SA must now confront the issue of developing services for the care and prevention of CDs to reduce the stagnating child mortality rates. ${ }^{[13]}$ The current IMR is now below 40/1 000 live births, at which point countries recognise the coming health needs of CDs and strive to implement appropriate services. ${ }^{[15]}$ The proportion of deaths from CDs in SA under-5s was $4 \%$ in $2008,{ }^{[3]}$ and may be expected to rise as childhood deaths from CDs increasingly emerge as a leading cause of death in children while deaths from infections, particularly HIV/AIDS, decrease.

Legislation entitles those affected and living with CDs, including those disabled as a result, to the 'best possible patient care' in the prevailing circumstances, and provides for access to prevention by appropriate interventions. ${ }^{[16]}$ With the global focus, including that of SA, shifting to non-communicable diseases, CDs must be contextualised as the first non-communicable disease experienced by people. CDs deserve to be prioritised, in accordance with WHA Resolution WHA63.17, to ensure the human dignity and constitutionally and legally enshrined human rights of those affected and their families. ${ }^{[2,17]}$

\section{H L Malherbe}

School of Clinical Medicine, College of Health Sciences, University of KwaZulu-Natal, Durban, South Africa, and National Chair, Southern African Inherited Disorders Association

\section{A L Christianson}

Division of Human Genetics, National Health Laboratory Service and Faculty of Health Sciences, University of the Witwatersrand, Johannesburg, South Africa

\section{Aldous}

School of Clinical Medicine, College of Health Sciences, University of KwaZulu-Natal, Durban, South Africa

\section{Corresponding author: H L Malherbe (helen@hmconsult.co.za)}

1. Christianson A, Howson CP, Modell B. March of Dimes: Global Report on Birth Defects, the Hidden Toll of Dying and Disabled Children. White Plains, NY: March of Dimes Birth Defects Foundation, 2006:85.

2. World Health Organization. Sixty-Third World Health Assembly - Birth Defects. Geneva: WHO, 2010. http://apps.who.int/gb/ebwha/pdf_files/WHA63/A63_R17-en.pdf (accessed 11 September 2013).

3. Nippert I, Christianson A, Gribaldo L, et al. Genetic Testing in Emerging Economies (GenTEE) Summary Report. Ispra, Italy: Joint Research Centre, European Commission, 2013:176.

4. Venter P, Christianson A, Hutamo C, Makhura M, Gericke G. Congenital anomalies in rural black South African neonates - a silent epidemic? S Afr Med J 1995;85(1):15-20.

5. Czeizel AE, Intôdy Z, Modell B. What proportion of congenital abnormalities can be prevented? BMJ 1993;306(6876):499-503. [http://dx.doi.org/10.1136/bmj.306.6876.499]

6. Omran AR. The epidemiologic transition: A theory of the epidemiology of population change. Milbank Mem Fund Q 1971;49(4):509-538. [http://dx.doi.org/10.2307/3349375]

7. Kahn K, Garenne ML, Collinson MA, Tollman SM. Mortality trends in a new South Africa:
. Kahn K, Garenne ML, Collinson MA, Tollman SM. Mortality trends in a new South Africa:
Hard to make a fresh start. Scand J Public Health Suppl 2007;35(69):26-34. [http://dx.doi. org/10.1080/14034950701355668]

8. Department of Health. Policy Guidelines for the Management and Prevention of Genetic Disorders, Birth Defects and Disabilities. Pretoria: Department of Health, 2001.

9. Department of Health. National Guidelines for the Care and Prevention of the Most Common Genetic Disorders, Birth Defects and Disabilities. Pretoria: Department of Health, 2004.

10. Smallman-Raynor M, Phillips D. Late stages of epidemiological transition: Health status in the developed world. Health Place 1999;5(3):209-222. [http://dx.doi.org/10.1016/S1353-8292(99)00010-6] 11. Agyei-Mensah S, de-Graft Aikins A. Epidemiological transition and the double burden of disease in Accra, Ghana. J Urban Health 2010;87(5):879-897. [http://dx.doi.org/10.1007/s11524-010-9492-y]

12. Kerber KJ, Lawn JE, Johnson LF, et al. South African child deaths 1990-2011: Have HIV services reversed the trend enough to meet Millennium Development Goal 4? AIDS 2013;27(16):2637-2648. reversed the trend enough to meet Millennium Developm
[http://dx.doi.org/10.1097/01.aids.0000432987.53271.40]

13. Dorrington R, Bradshaw D, Laubscher, R. Rapid Mortality Surveillance Report 2012. Dorrington R, Bradshaw D, Laubscher, R. Rapid Mortality Surveillance Report 2012.
Cape Town: South African Medical Research Council, 2012. http://www.mrc.ac.za/bod/ Cape Town: South African Medical Research Council, 2012.
RapidMortalitySurveillanceReport2012.pdf (accessed 29 October 2014)

RapidMortalitySurveillanceReport2012.pdf (accessed 29 October 2014)
14. Department of Health. Strategic Framework for the Modernisation of Tertiary Hospital Services. Department of Health. Strategic Framework for the Moder
Discussion Document. Pretoria: Department of Health, 2003.

Discussion Document. Pretoria: Department of Health, 2003 .
15. Modell M, Kuliev A. The history of community genetics: The contribution of the haemoglobin 5odell M, Kuliev A. The history of community genetics: The contribution of the
disorders. Community Genet 1998;1(1):3-11. [http://dx.doi.org/10.1159/000016129]

16. World Health Organization, World Alliance of Organizations for the Prevention of Birth Defects. Services for the Prevention and Management of Genetic Disorders and Birth Defects in Developing Countries (Report of a Joint WHO/WAOPBD Meeting, The Hague, 5-7 January 1999). Geneva: WHO, 1999.

17. Christianson AL. Attaining human dignity for people with birth defects: A historical perspective. S Afr Med J 2013;103(12):1014-1019. [http://dx.doi.org/10.7196/samj.7277]

18. UN Inter-agency Group for Child Mortality Estimation (IGME). Child mortality estimates. www. childmortality.org (accessed 3 November 2014).

9. World Bank. Life expectancy at birth total (years). http://data.worldbank.org/indicator/SP.DYN.LE00. IN (accessed 2 November 2014).

20. Health Systems Trust. 2012 National Antenatal Sentinel HIV \& Herpes Simplex Type-2 Prevalence Survey. www.hst.org.za/publications/2012-national-antenatal-sentinel-hiv-herpes-simplex-type-2prevalence-survey (accessed 4 November 2014).

S Afr Med J 2015;105(3):186-188. DOI:10.7196/SAMJ.9136 